\title{
Similar Trait Structure and Vulnerability in Pelagic Fish Faunas on Two Remote Islands
}

\section{Madeline Steinberg}

Institute of Zoology of the Zoological Society of London

\section{Jean-Baptiste Juhel}

MARBEC: Centre pour la Biodiversite Marine l'Exploitation et la Conservation

\section{Virginie Marques}

MARBEC: Centre pour la Biodiversite Marine l'Exploitation et la Conservation

\section{Clara Péron}

Muséum National d'Histoire Naturelle: Museum National d'Histoire Naturelle

\section{Régis Hocdé}

MARBEC: Centre pour la Biodiversite Marine l'Exploitation et la Conservation

\section{Andrea F Polanco}

Museo Nacional de Historia Natural de Columbia

\section{Loïc Pellissier}

MARBEC: Centre pour la Biodiversite Marine l'Exploitation et la Conservation

\section{Sébastien Villéger}

MARBEC: Centre pour la Biodiversite Marine l'Exploitation et la Conservation

\section{David Mouillot}

MARBEC: Centre pour la Biodiversite Marine l'Exploitation et la Conservation

\section{Tom B Letessier ( $\sim$ Tom.Letessier@ioz.ac.uk)}

Institute of Zoology of the Zoological Society of London https://orcid.org/0000-0003-4011-0207

\section{Research Article}

Keywords: Biodiversity, Functional diversity, Pelagic fish, Islands, Mid-water BRUVS

Posted Date: May 28th, 2021

DOl: https://doi.org/10.21203/rs.3.rs-435131/v1

License: (a) (i) This work is licensed under a Creative Commons Attribution 4.0 International License. Read Full License 


\section{Abstract}

The link between biodiversity and ecosystem functioning has been the topic of considerable research, but it remains unclear how biodiversity decline is compromising ecosystem functionality, particularly in the pelagic realm. Here, we explore how pelagic fish species diversity relates to functional diversity by sampling two locations, which, on the basis of biogeography, environmental conditions, and human pressures, were expected to host pronounced differences in species composition and abundances, and therefore functionality. Strings of five drifting mid-water Baited Remote Underwater Video Systems were used to survey pelagic vertebrate diversity and abundance in two isolated oceanic island systems, the Malpelo Fauna and Flora Sanctuary - a large, 25-year-old marine protected area - and an unprotected area in Cape Verde. Functional diversity, which offers insight into a community's resilience against disturbance, was analysed using six key functional traits of marine fishes. Cape Verde showed high overall abundance (Total MaxN 873) and low biomass (3,559 kg), with a predominance of smaller fishes. Malpelo showed high biomass $(7,839 \mathrm{~kg}$ ) but lower abundance (Total MaxN 465), with a predominance of large species. Species and functional diversity were marginally different between locations. Multivariate analysis of species relative abundances showed significant divergence between locations, although community functional traits overlapped strongly, suggesting that both communities share a similar structure and vulnerability. The existence of a common functional 'backbone' in diverging species communities across the oceans, under different productivity regimes, and under different protection levels, suggests that although pelagic communities may differ considerably in terms of species composition, this does not translate into a differing functional structure and resilience potential. Whether this vulnerability is a common feature of pelagic communities and how this contrasts with benthic systems warrants further research.

\section{Introduction}

The pelagic realm is the world's largest habitat, covering $71 \%$ of Earth's surface $\left(1368.10^{6} \mathrm{~km}^{2}\right)$, and providing millions of tons of fish biomass annually (Chassot et al. 2010). Pelagic systems have a massive influence on global nutrient cycling, food production, and climate change, each of which may be influenced by the abundance and composition of pelagic communities (Duffy \& Stachowicz 2006, Sala et al. 2021). Yet, the vast pelagic area with dynamic environmental conditions (Breitburg et al. 2018)) and heterogeneous distribution of animals (Denderen et al. 2018) make it difficult to monitor and understand pelagic faunas(Briscoe et al. 2016), challenging the design of marine protected areas (Sala et al. 2021) and the appropriate management of fisheries (Pons et al. 2018).

Pelagic ecosystems hold unique characteristics compared to the benthos, with likely implication for vulnerability and resilience. While pelagic diversity is considered relatively low compared with that of demersal fish communities (Tittensor et al. 2010), pelagic communities may show high local diversity, as a function of biogeography, bathymetry, and productivity (Bouchet et al. 2020). Oceanic islands, banks, and seamounts are notable hotspots of species richness (Letessier et al. 2019), which predictably aggregate fish biomass, including mobile predators, by acting as navigation points and reliable feeding 
grounds (Hosegood et al. 2019). Because prey density in the open ocean is generally low, predators need to forage over a wide range to fulfil their energetic requirements, leading to resource translocation from other habitats and promoting food web connectivity (Huepel et al. 2014).

Ecosystem functioning and resilience are increasingly assessed using trait-based analyses (McLean et al. 2019), an approach that determines which functional roles are being filled and by which species (Mouillot et al. 2013). At the community level, functional traits explain differences of vulnerability between species: for example, predators and large individuals may be preferentially targeted by fishing (Mbaru et al. 2020). In the face of increasing fisheries pressure and environmental change, a trait-based approach may capture novel aspects of pelagic community vulnerability missed by classic community-based analyses. However, it remains unclear to which degree different pelagic systems are similarly vulnerable, due in part because of limited pelagic sampling methodologies (Letessier et al. 2017).

Here, we use mid-water Baited Remote Underwater Video Systems (BRUVS, Bouchet \& Meeuwig 2015) to assess how pelagic fish communities differ taxonomically and functionally. Our study took place in Malpelo Island and in Cape Verde, two remote tropical islands located in different biogeographical provinces (Kulbicki et al., 2013) which are exposed to contrasting levels of both environmental conditions and human pressures. We hypothesise that species community differences in taxonomy and relative abundance at each location may lead to trait dissimilarity, with implication for resilience and vulnerability.

Our objectives were to 1) describe and contrast species communities on each island using mid-water BRUVS and multivariate analyses, and 2) assess the extent to which any species dissimilarity translates into functional dissimilarity, using multivariate trait-based analyses, and then (3) make general inference concerning pelagic vulnerability.

\section{Materials And Methods}

\section{Study locations}

Our study took place at Malpelo Island and Cape Verde (Fig. 1A). Malpelo is a remote oceanic island located in the Tropical Eastern Pacific, approximately $500 \mathrm{~km}$ west of Buenaventura, Colombia. The interaction of multiple seasonal currents results in distinct cold and warm water seasons at Malpelo (Bessudo et al. 2011). Sampling took place during the cold season, which occurs between January and April and is characterized by a shallow thermocline - around $15 \mathrm{~m}$ depth - decreased visibility due to high primary production caused by upwelling, and an average sea surface temperature of about $25^{\circ} \mathrm{C}$ (Soler et al. 2013). An area of $8,575 \mathrm{~km}^{2}$ surrounding Malpelo is designated as the Malpelo Flora and Fauna Sanctuary, an MPA since 1995 (UNESCO 2019). Though it is a no-take MPA, some illegal, unreported, and unregulated (IUU) fishing activity is believed to occur (Bessudo et al. 2011).

The Republic of Cape Verde is an archipelago nation located around $600 \mathrm{~km}$ west of Senegal, with a population of approximately 550,000 (United Nations 2019). It falls within the Tropical Eastern Atlantic biogeographic region and is subject to the seasonal influences of both the Canary Current and the North 
Equatorial Countercurrent (Wirtz et al. 2008). Average sea surface temperature during the warmer months in Cape Verde is around $27^{\circ} \mathrm{C}$ (Stobberup et al. 2004). Domestic artisanal and commercial fishing occur throughout the area, including vessels flagged from the European Union and China (Medina et al. 2015). Substantial IUU fishing also contributes to overall fisheries landings (Medina et al. 2015). Pelagic target species include tuna, billfish and mackerel scad, with sharks as important bycatch (Santos et al. 2013).

\section{Sampling protocol}

The pelagic community in each location was assessed using drifting mid-water BRUVS (Bouchet \& Meeuwig 2015). Each rig consisted of a metal frame with two GoPro cameras in underwater housings mounted on a bar perpendicular to an arm supporting a bait canister filled with $1 \mathrm{~kg}$ of crushed fish (tuna and mackerel). The two cameras were intended to be used for stereo measurements, but could not be calibrated in the field, so only footage from the right-hand camera of each rig was used for analysis. The rigs were suspended from buoys at a depth of $10 \mathrm{~m}$ (Bouchet \& Meeuwig 2015). BRUVS rigs were deployed in groups of five - hereafter referred to as "strings" - with each rig connected to the next one by a $200 \mathrm{~m}$ line. This distance was a trade-off between field practicalities and maximising the distance between rigs (Bouchet et al. 2018). The strings were allowed to drift for approximately two hours, an effective duration for mid-water BRUVS (Bouchet et al. 2018). Eight strings - a total of 40 individual rigs - were deployed in Malpelo and a total of nine strings - 44 individual rigs, as one string had only 4 rigs were deployed in Cape Verde.

The deployment sites targeted features such as islands and seamounts known to provide key habitat for top predators and migratory species (Nalesso et al. 2019). The survey at Malpelo was conducted between 18 and 28 March 2018, 8:00 AM to 5:00 PM local time. BRUVS were deployed at four sites around the island, located within $3^{\circ} 57^{\prime} 5.184^{\prime \prime}$ to $4^{\circ} 1^{\prime} 46.704^{\prime \prime} \mathrm{N}$, and $81^{\circ} 40^{\prime} 8.256^{\prime \prime}$ to $81^{\circ} 35^{\prime} 47.4^{\prime \prime} \mathrm{W}$, with depths ranging from $25 \mathrm{~m}$ to $1500 \mathrm{~m}$ (Fig. 1). The survey in Cape Verde took place from 27 September to 1 October 2017, 9:00 AM to 4:30 PM local time, focusing on the areas southwest of the island of Boa Vista, and the João Valente Bank seamount. The sampling areas were located between $15^{\circ} 47^{\prime} 40.452^{\prime \prime}$ to $16^{\circ} 0^{\prime} 25.2^{\prime \prime} \mathrm{N}$, and $23^{\circ} 12^{\prime} 17.316^{\prime \prime}$ to $22^{\circ} 56^{\prime} 11.148^{\prime \prime} \mathrm{W}$, with depths ranging from 25 to $500 \mathrm{~m}$ (Fig. 1).

\section{Data analyses}

The BRUVS footage was analysed using the video analysis software VidSync (Neuswanger et al. 2016). Analysis began when the camera settled underwater and ended when the duration of the recording reached two hours. Species were identified to the lowest possible taxonomic level using information and photographs available from reference books and FishBase (Froese \& Pauly 2019, Humann \& DeLoach 2004, Humann \& DeLoach 2014). Where species-level identifications could not be made, genus or family names were used. For each species, we recorded MaxN, the maximum number of individuals present in a single frame, thereby preventing double-counting (Bouchet et al. 2018). Due to the proximity between each rig, abundance for each species was reported at the level of the string, using the maximum MaxN value across each rig (Bouchet et al. 2018). We opted for this approach as $200 \mathrm{~m}$ separation between rigs is probably not sufficient to guarantee independence, certainly not for large sharks, which can cover more 
than this distance during the 2-hour soak time. In the absence of stereo measurements, the biomass of each species was computed using common lengths and Bayesian length-weight coefficients available from FishBase and scaled by abundance (Table S1). These biomass estimates are speculative since they are based on calculations from FishBase rather than true measurements. The conclusions on biomass patterns from this study are therefore rough estimates. Future studies should include stereo measurements to more accurately assess patterns in fish biomass.

Total abundance and biomass by deployment or site were analysed using PERMANOVA. The differences between species communities at each site were tested with an analysis of similarities (ANOSIM) on BrayCurtis dissimilarity between all pairs of communities. A similarity percentage (SIMPER) analysis using Bray-Curtis dissimilarity and 1,000 permutations were used to compare species groups by site. Species community abundance and biomass were illustrated using non-metric multidimensional scaling (NMDS).

Each species was functionally described using a set of 6 complementary traits describing their key ecological features (Mouillot et al. 2014, Villéger et al. 2017). The traits were size, mobility, period of activity, schooling, position in water column, and diet (Table S2). Values for the adult stage of each species were gathered from FishBase and other literature (Supplementary material). A multidimensional functional space was calculated following the methods of Maire et al. (2015), Mouillot et al. (2013), and Villéger et al. (2014), using custom R scripts by Villéger available online (http://villeger.sebastien.free.fr/Rscripts.html). A dissimilarity matrix quantifying the functional distance between species was computed using Gower's distance, which is able to accommodate categorical traits (Maire et al. 2015). A Principal Coordinates Analysis (PCoA) was performed with this matrix, and the mean squared deviation (mSD) was used to select the best quality functional space. The mSD quantifies the "mean squared deviation between the initial functional distance and the scaled distance in the functional space" and - when using Gower's distance - ranges from 0 to 1, the closest value to zero indicating the most robust functional space (Maire et al. 2015). The four-dimensional space - or the space using the first four axes of the PCoa - is typically the highest quality space (Maire et al. 2015). Our four-dimensional space had an mSD of 0.0026 (Fig. S1).

Three complementary functional diversity indices were calculated using species position in the multidimensional space: functional richness (FRic), functional evenness (FEve), and functional divergence (FDiv) (Villéger et al. 2008). These metrics are favoured for functional diversity analysis because they can work with multiple traits. FRic measures how much functional space is filled by a species community and accounts only for species position in the multidimensional range. FEVe and FDiv account for species abundance and measure regularity and variance within the occupied space, respectively (Villéger et al. 2008). To further explore functional overlap between communities, functional beta-diversity and its percentage due to species turnover were computed using Jaccard's dissimilarity index (Villéger et al. 2013). All analyses were performed in R statistical software (R Core Team 2018).

\section{Results And Discussion}


In line with expectations, we observed distinct species compositions between locations. BRUVS observations yielded 29 fish species and one mammal (family Delphinidae), with 18 species present in Malpelo and 19 species present in Cape Verde (Fig. 2A). Species ubiquitous to both sites were wahoo (Acanthocybium solandri), silky shark (Carcharhinus falciformis), mackerel scad (Decapterus sp.), amberjack (Seriola sp), and juveniles of family Carangidae. Cape Verde hosted fewer species (5.22 \pm 2.11 SD per string) than Malpelo (6.25 $\pm 2.19 \mathrm{SD}$ ), albeit not significantly (PERMANOVA $F_{1,15}=0.3011$, $p$-value $=0.773$ ). Abundance was higher in Cape Verde (873 individuals total, mean $97 \pm 128.9$ SD per string), than in Malpelo (465 individuals total, mean $58.1 \pm 59.9$ SD per string), whereas biomass in Malpelo (7,838 kg total, mean $979.8 \pm 506.3$ SD per string) far exceeded the biomass observed in Cape Verde $(3,558 \mathrm{~kg}$ total, mean $395.44 \pm 563.1 \mathrm{SD}$ per string, Fig. 2B). An ANOSIM test revealed significantly dissimilar clusters between locations ( $R=0.5, p=0.001$, Fig. $3 A$ and $B$ ). Fifteen species were responsible for $95 \%$ of the dissimilarity between sites (Table S3, SIMPER). Mackerel scad (Decapterus sp.), rainbow runner (Elagatis bipinnulata), yellowfin tuna (Thunnus albacares), and little tunny (Euthynnus alletteratus) cumulatively contributed $55 \%$ of the difference in abundance between Cape Verde and Malpelo, while rainbow runner, yellowfin tuna, scalloped hammerhead (Sphyrna lewini), and cornetfish (Fistularia sp.) contributed significantly too $(p<0.05)$.

In contrast with expectations, communities from the two locations filled the same amount of the functional space (functional richness Malpelo: 0.542, Cape Verde: 0.452), and species abundance were similarly distributed in the filled space (functional divergence: Malpelo: 0.833, Cape Verde 0.913) in both locations. While the volume of the overall space occupied by each location was relatively high, the majority of the species were densely distributed in one area of the space, displaying low functional evenness ( 0.425 for Cape Verde, and 0.346 for Malpelo). The first two dimensions showed most species clustered on the right-hand side (Fig. 3C), defined by mobility, whereas the outliers on the left side of the space had a more restricted range (Fig. S2A). Highly mobile species, clustered into two groups, one characterised by purely pelagic species of very small, and medium size, and with a planktivorous or omnivorous diet and one by large or very large, benthopelagic species living solitary or in small groups, and with either a piscivorous or invertivorous diet. The third and fourth dimensions of the functional space showed some of the same stratification observed on the first two dimensions. However, the species which diverged from the main group were planktivores and invertivores which fed on mobile prey (Fig. 3D), with loose grouping according to different daily activity patterns (Fig. S2B).

Functional divergence and functional evenness are indices of the variance and regularity of species' distribution within the functional space, respectively, weighted by abundance (Villéger et al. 2008). A highly divergent and minimally even community is one in which some functional roles are much better represented and insured than others, which leaves points of exposure to disturbance, particularly when as was the case here - dominant and common species are sensitive (McLean et al. 2019). Two of the most abundant species observed at either location are currently on the IUCN Red List Red, namely yellowfin tuna (Near Threatened) and Atlantic horse mackerel (Vulnerable; IUCN 2020). Furthermore, 
ubiquitous top predators like the silky shark and scalloped hammerhead, essential to ecosystem functioning, are Red Listed as Vulnerable and Critically Endangered, respectively (IUCN 2020).

Overall functional beta-diversity between the locations was 0.6 , to which species turnover contributed $90.3 \%$. The remaining proportion arose from distinct trait combinations, often between confamilials like the triggerfishes (mobile in Malpelo, and reef-associated in Cape Verde), surgeonfishes (large in Malpelo and small in Cape Verde) and jacks (large and piscivorous in Malpelo, and medium and invertivore in Cape Verde). Fishing remains the primary threat to pelagic elasmobranchs and teleosts (Pacoureau et al 2021). Although the bulk of the functional space was similar between locations, the presence of such unique trait combinations suggests that some nuanced differences in sensitivity may still render certain locations more or less resilient (Villéger et al. 2013). Future research should aim to identify pelagic systems which overperform compared to expectations, in order to identify unique resilient traits associated with either positive or negative ecosystem outcomes (Cinner et al., 2016).

Our survey, although limited in spatio-temporal scale, included different biogeographical provinces and covers contrasting ends of environmental and human pressure gradients. It presents evidence that pelagic ecosystems may share a common 'backbone' of functional traits related to mobility and predatory diet. Such a backbone of 21 common traits has already been documented to exist within global reef ecosystems (McLean et al. 2021). Since ecological disturbance is likely to affect species with identical functional traits in similar ways (Mouillot et al. 2013), low trait diversity within pelagic ecosystems may make the pelagic faunas particularly vulnerable to disturbance. We propose that further study specifically aims to determine whether this is a universal feature of the pelagic realm, and the degree to which it may affect the resilience of mid-water communities.

\section{Declarations}

Acknowledgements

We thank Monaco Explorations for supporting the fieldwork and The Bertarelli Foundation for TBL's time and salary in the field. We are grateful to the Master and Crew of the RV Yersin for supporting sampling activities. We thank Dr. Christophe Eizaguirre for his support as a teacher and adviser to MS.

\section{Fundings}

Field activities were funded by Monaco Explorations. The Bertarelli Foundation funded TBL's salary Conflict of interest

We declare no conflict of interest 
Ethics approval

As none of the authors are resident in Cape Verde, research there was conducted under authorization No. 08/GP-CA.AMP/2017.

Data/Code availability

All code is referenced in the text

Author's contribution

MS conceived and conducted the analysis, and as part of her MSc thesis. TBL supervised and managed the study and completed the first draft. TBL, JB, RH, LP, CP, AP, and VM collected samples in the field. DM and SV advised on the functional analysis. DM is the PI of the Monaco Exploration 'Megafauna' team. All authors helped revise the manuscript.

\section{References}

1. Bessudo S, Soler GA, Klimley AP, Ketchum JT, Hearn A, Arauz R (2011) Residency of the scalloped hammerhead shark (Sphyrna lewini) at Malpelo Island and evidence of migration to other islands in the Eastern Tropical Pacific. Environ Biol Fishes 91:165-176

2. Breitburg D, Levin LA, Oschlies A, Grégoire M, Chavez FP, Conley DJ et al (2018) Declining oxygen in the global ocean and coastal waters. Science, 359(6371)

3. Briscoe DK et al (2016) Are we missing important areas in pelagic marine conservation? Redefining conservation hotspots in the ocean. Endanger Species Res 29:229-237

4. Bouchet PJ, Meeuwig JJ (2015) Drifting baited stereo-videography: A novel sampling tool for surveying pelagic wildlife in offshore marine reserves. Ecosphere 6:137

5. Bouchet PJ et al (2018) Marine sampling field manual for pelagic stereo-BRUVS (Baited Remote Underwater Videos). In: Przeslawski R, Foster S (eds) Field Manuals for Marine Science Sampling to Monitor Australian Waters. National Environmental Science Programme (NESP), p 105-132

6. Bouchet PJ, Letessier TB, Caley JM, Nichol, Nichol S, Hemmi JM, Meeuwig JJ (2020) Submerged Carbonate Banks Aggregate Pelagic Megafauna in Offshore Tropical Australia. Frontiers in Marine Science, 1-17

7. Chassot E, Bonhommeau S, Dulvy NK, Mélin F, Watson R, Gascuel D, Le Pape O (2010) Global marine primary production constrains fisheries catches. Ecol Lett 13(4):495-505

8. Cinner, J. E., Huchery, C., MacNeil, M. A., Graham, N. A. J., McClanahan, T. R., Maina, J., et al. (2016). Bright spots among the world's coral reefs. Nature, 535, 416-419. http://doi.org/10.1038/nature18607

9. Global patterns in marine predatory fish (2018) Global patterns in marine predatory fish., 2(1), 6570. http://doi.org/10.1038/s41559-017-0388-z 
10. Duffy JE, Stachowicz JJ (2006) Why biodiversity is important to oceanography: potential roles of genetic, species, and trophic diversity in pelagic ecosystem processes. Mar Ecol Prog Ser 311:179189

11. Froese R, Pauly D (2019) FishBase. www.fishbase.org (accessed 2 Feb 2019)

12. Heupel MR, Knip DM, Simpfendorfer CA, Dulvy NK (2014) Sizing up the ecological role of sharks as predators. Mar Ecol Prog Ser 495:291-298

13. Hosegood PJ, Nimmo-Smith WAM, Proud R, Adams K, Brierley AS (2019) Internal lee waves and baroclinic bores over a tropical seamount shark "hot-spot. Prog Oceanogr 172:34-50

14. Humann P, DeLoach N (2004) Reef Fish Identification: Baja to Panama. New World Publications, Jacksonville

15. ï»¿Humann P, DeLoach N (2014) Reef Fish Identification: Florida, Caribbean, Bahamas. New World Publications, Jacksonville

16. IUCN (2020) The IUCN Red List of Threatened Species. Version 2020-3. www.iucnredlist.org (accessed 10 February 2021)

17. Kulbicki M et al (2013) Global biogeography of reef fishes: A hierarchical quantitative delineation of regions. PLOS ONE 8:e81847

18. Letessier TB et al (2019) Remote reefs and seamounts are the last refuges for marine predators across the Indo-Pacific. PLOS Biol 17:e3000366

19. Letessier TB, Bouchet P, Meeuwig JJ (2017) Sampling mobile oceanic fishes and sharks: implications for fisheries and conservation planning. Biol Rev 92(2):627-646

20. Maire E, Grenouillet G, Brosse S, Villéger S (2015) How many dimensions are needed to accurately assess functional diversity? A pragmatic approach for assessing the quality of functional spaces. Glob Ecol Biogeogr 24:728-740

21. Mbaru EK, Graham NAJ, McClanahan TR, Cinner JE (2020) Functional traits illuminate the selective impacts of different fishing gears on coral reefs. J Appl Ecol 57(2):241-252.

http://doi.org/10.1111/1365-2664.13547

22. McLean M, Auber A, Graham NAJ, Houk P, Villéger S, Violle C, Thuiller W, Wilson SK, Mouillot D (2019) Trait structure and redundancy determine sensitivity to disturbance in marine fish communities. Glob Chang Biol 25:3424-3437

23. McLean M, Auber A, Graham NAJ, Houk P, Villéger S, Violle C et al (2019) Trait structure and redundancy determine sensitivity to disturbance in marine fish communities. Glob Change Biol 25(10):3424-3437

24. McLean M, Stuart-Smith RD, Villéger S, Auber A, Edgar GJ, MacNeil MA et al (2021) Trait similarity in reef fish faunas across the world's oceans oceans. Proceedings of the National Academy of Sciences, 118(12), e2012318118

25. Medina A, Gomes I, Araujo S, Lima L, Monteiro R (2015) Fifth National Report on the Status of Biodiversity in Cabo Verde. Convention on Biological Diversity, Montreal 
26. Mouillot D, Graham NAJ, Villéger S, Mason NWH, Bellwood DR (2013) A functional approach reveals community responses to disturbances. Trends Ecol Evol 28:167-177

27. Mouillot D et al (2014) Functional over-redundancy and high functional vulnerability in global fish faunas on tropical reefs. Proc Natl Acad Sci USA 111:13757-13762

28. Nalesso E et al (2019) Movements of scalloped hammerhead sharks (Sphyrna lewini) at Cocos Island, Costa Rica and between oceanic islands in the Eastern Tropical Pacific. PLOS ONE 14:1-16

29. Neuswanger JR, Wipfli MS, Rosenberger AE, Hughes NF (2016) Measuring fish and their physical habitats: versatile 2D and 3D video techniques with user-friendly software. Can J Fish Aquat Sci 73:1861-1873

30. Pacoureau N, Rigby CL, Kyne PM, Sherley RB, Winker H, Carlson JK et al (2021) Half a century of global decline in oceanic sharks and rays. Nature, 1-21

31. Pons M, Melnychuk MC, Hilborn R (2018) Management effectiveness of large pelagic fisheries in the high seas. Fish Fish 19(2):260-270

32. R Core Team (2019) R: a language and environment for statistical computing. R Foundation for Statistical Computing, Vienna

33. Sala E, Mayorga J, Bradley D, Cabral RB, Atwood TB, Auber A et al (2021) Protecting the global ocean for biodiversity, food and climate. Nature, 1-15

34. Santos IT, Monteiro CA, Harper S, Zylich K, Zeller D, Belhabib D (2013) Reconstruction of marine fisheries catches for the Republic of Cape Verde. In: Belhabib D, Zeller D, Harper S, Pauly D (eds) Marine Fisheries catches in West Africa, 1950-2010, part I. Fisheries Centre Research Reports, Vancouver, pp 79-90

35. Soler G, Bessudo S, Guzman A (2013) Long term monitoring of pelagic fishes at Malpelo Island, Colombia. Lat Am J Conserv 3:28-37

36. Stobberup KA, Ramos VDM, Coelho ML (2004) Ecopath Model of the Cape Verde coastal ecosystem. In: Palomares MLD, Pauly D (eds) West African marine ecosystems: models and fisheries impacts. Fisheries Centre Research Reports, Vancouver, pp 39-56

37. Tittensor DP, Mora C, Jetz W, Lotze HK, Ricard D, Berghe EV, Worm B (2010) Global patterns and predictors of marine biodiversity across taxa. Nature 466(7310):1098-1101

38. UNESCO. Malpelo Fauna and Flora Sanctuary - UNESCO World Heritage Centre 1992-2018. whc.unesco.org/en/list/1216 (accessed 31 May 2019)

39. United Nations, Department of Economic and Social Affairs, Population Division (2019) World Population Prospects 2019. Custom data acquired via website (accessed 20 May 2019)

40. Villéger S, Brosse S, Mouchet M, Mouillot D, Vanni MJ (2017) Functional ecology of fish: current approaches and future challenges. Aquat Sci 79:783-801

41. Villéger S, Grenouillet G, Brosse S (2014) Functional homogenization exceeds taxonomic homogenization among European fish assemblages. Glob Ecol Biogeogr 23:1450-1460 
42. Villéger S, Mason NWH, Mouillot D (2008) New multidimensional functional diversity indices for a multifaceted framework in functional ecology. Ecology 89:2290-2301

43. Villéger S, Grenouillet G, Brosse S (2013) Decomposing functional $\beta$-diversity reveals that low functional $\beta$-diversity is driven by low functional turnover in European fish assemblages. Glob Ecol Biogeogr 22:671-681

44. Wirtz P, Fricke R, Biscoito MJ (2008) The coastal fishes of the Cape Verde Islands - New records and an annotated check-list. Zootaxa 1715:1-26

\section{Figures}

A
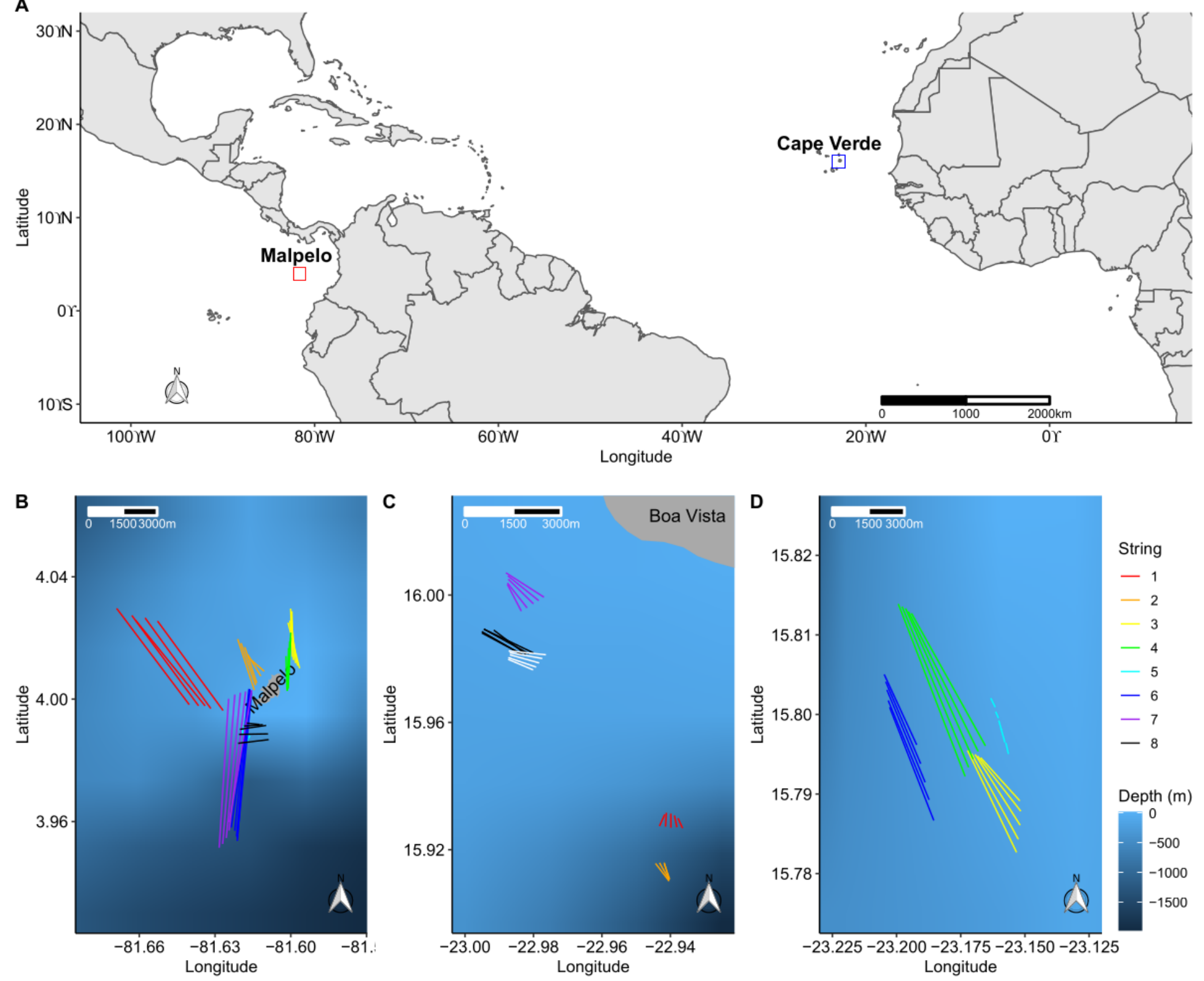

Figure 1 
Sampling locations and deployment sites. Sampling locations (A) and BRUVS deployment sites in Malpelo (B) and Cape Verde (C, D). Line segments indicate BRUVS trajectories and are color-coded by string, with each line representing an individual rig. Note: The designations employed and the presentation of the material on this map do not imply the expression of any opinion whatsoever on the part of Research Square concerning the legal status of any country, territory, city or area or of its authorities, or concerning the delimitation of its frontiers or boundaries. This map has been provided by the authors.

A

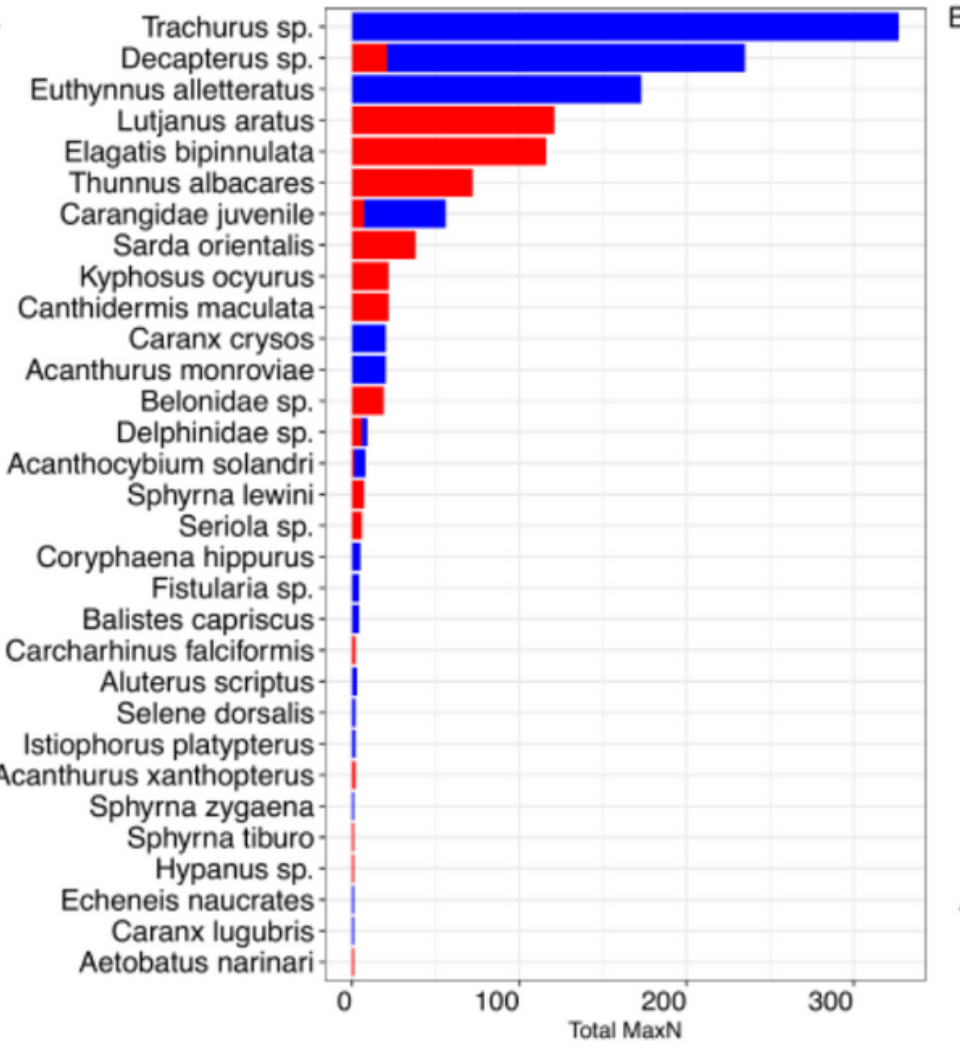

B

Thunnus albacares Sphyrna lewiniDelphinidae sp. Euthynnus alletteratus Elagatis bipinnulata Carcharhinus falciformis Istiophorus platypterus Acanthocybium solandri Sphyrna zygaena Decapterus sp.

Belonidae sp.

Sarda orientalis

Aetobatus narinari

Lutjanus aratus

Canthidermis maculata

Acanthurus monroviae

Coryphaena hippurus

Trachurus sp. Seriola sp.

Fistularia sp.

Caranx crysos

Kyphosus ocyurus

Balistes capriscus Caranx lugubris Hypanus sp.

Aluterus scriptus

Sphyrna tiburo

Echeneis naucrates Acanthurus xanthopterus

Selene dorsalis Carangidae juvenile

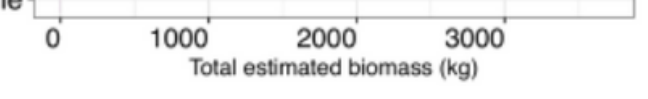

Cape Verde

Malpelo

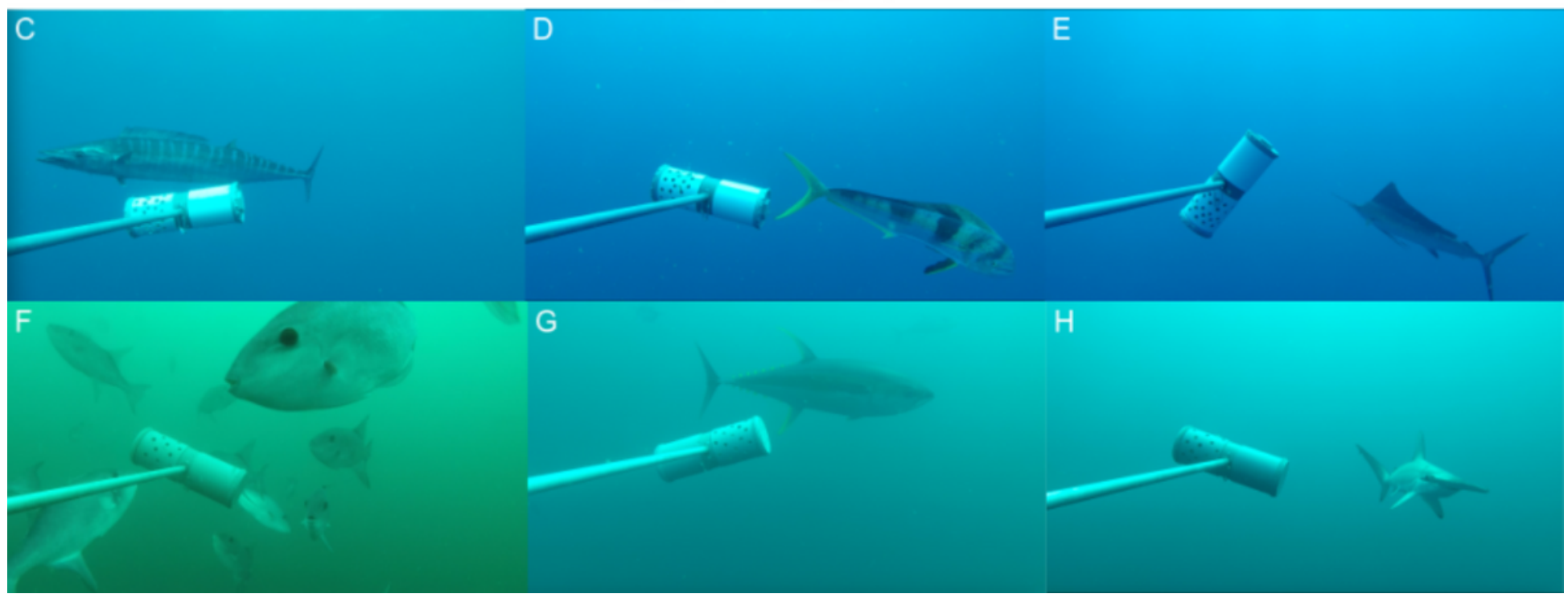

\section{Figure 2}


Fish community composition in Malpelo and Cape Verde. Ranked abundance (A) and biomass (B) of species recorded in either locations, and examples of species observed using BRUVS. Stills (C) through (E) are from Cape Verde: (C) Acanthocybium solandri - Wahoo; (D) Coryphaena hippurus - Common dolphinfish; (E) Istiophorus platypterus - Indo-Pacific sailfish. Stills $(F)$ through $(H)$ are from Malpelo: $(F)$ Canthidermis maculata - Rough triggerfish; $(G)$ Thunnus albacares - Yellowfin tuna; $(H)$ Sphyrna lewini

- Scalloped hammerhead.
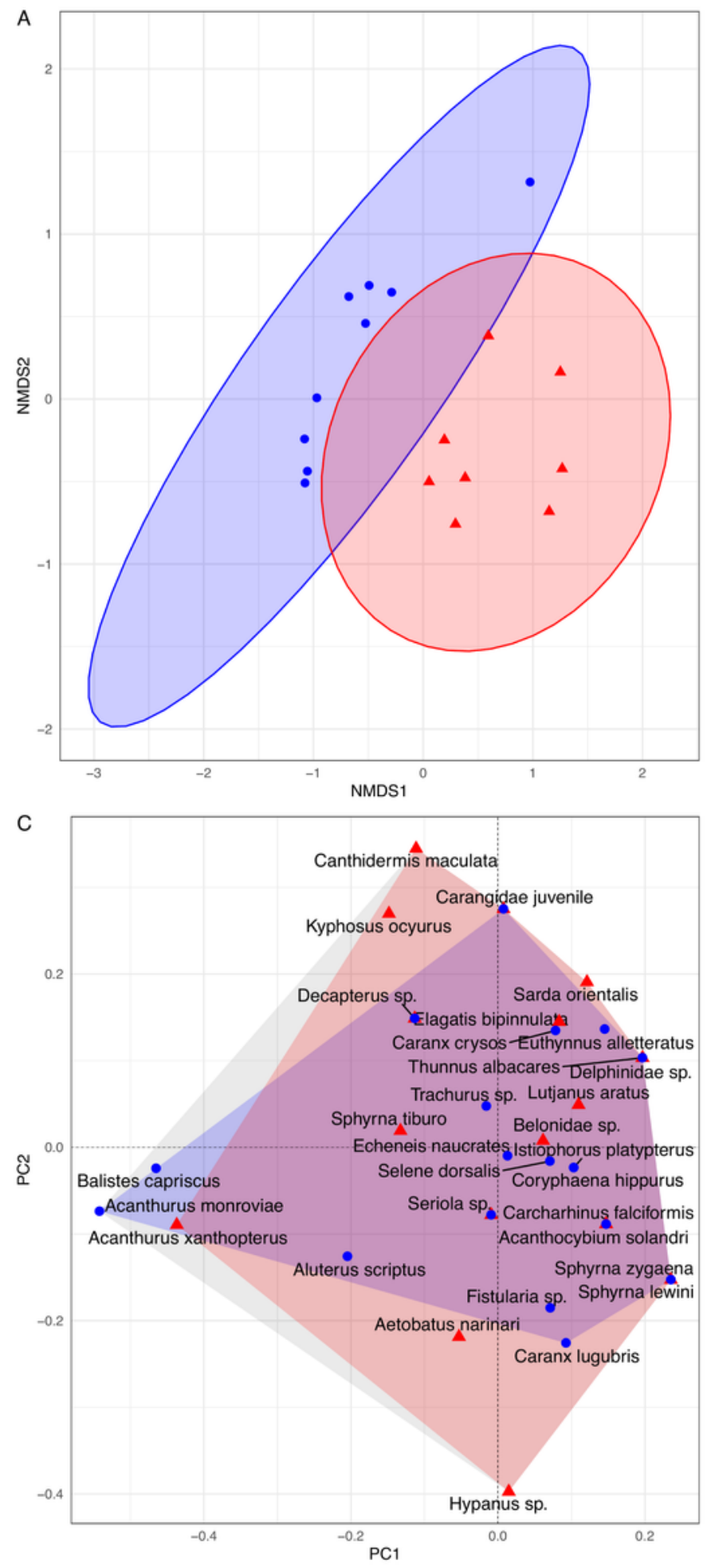

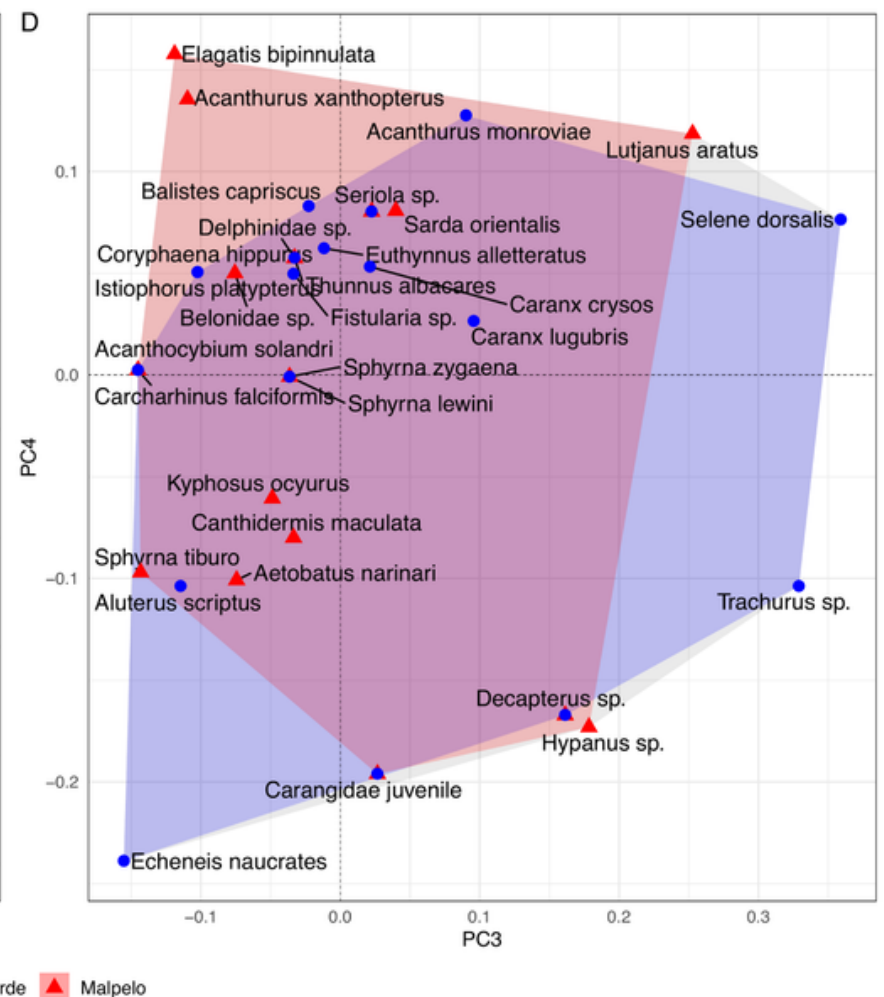

Figure 3 
Species community differences and functional similarity in Malpelo and Cape Verde. Two-dimensional NMDS ordination plot with $95 \%$ confidence level ellipses based on ANOSIM results from samples (BRUVS strings) from Cape Verde and Malpelo (A). NMDS plot of samples with vectors showing species correlation (B). Distribution of species in the first and second (C) and third and fourth (D) dimensions of the functional space. Grey hull indicates overall volume of the functional space on the two axes shown. Red (Malpelo) and blue (Cape Verde) hulls contain positions of all species found at each site.

\section{Supplementary Files}

This is a list of supplementary files associated with this preprint. Click to download.

- SteinbergMarBFunBRUVSSupp20210308.docx 